\title{
Using Bond-Graph technique for modelling and simulating railway drive systems.
}

\author{
J. Lozano, J. Felez, J:M. Mera, J.D. Sanz \\ ETSI Engineering, Universidad Politecnica de Madrid \\ Madrid, Spain \\ e-mail: joseantonio.lozano@upm.es, jesus.felez@upm.es, josemanuel.mera@upm.es, juandedios.sanz@upm.es
}

\begin{abstract}
This work presents the application of BondGraph Technique to modelling and simulating the behaviour of railway transport as a tool for studying its dynamic behaviour, consumption and energy efficiency, and environmental impact. The basic aim of this study is to make a contribution to the research and innovation into new technologies that will lead to the discovery of ever more efficient environmentally-friendly transport.

We begin with an introduction to the study of longitudinal train dynamics as well as a description of the most currently used railway drive systems. Bond-Graph technique enables this modelling to be done systematically taking into account all the fields of science and technology involved while bringing together all the mechanical, electrical, electromagnetic, thermal, dynamic and regulatory aspects. Once the models have been developed, the behaviour of the drive systems is simulated by reproducing actual railway operating conditions along a standard section of track. Through a detailed study of the simulation results and choosing the most significant parameters, a comparison can be made of how the different systems perform. We end with the most important conclusions from which it can be deduced which drive systems are comparatively more efficient and environmentally-friendly.
\end{abstract}

Keywords- Bond-Graph, transport, railway, energy efficiency, environmental impact.

\section{INTRODUCTION. LONGITUDINAL TRAIN DYNAMICS}

There is an extensive bibliography on the longitudinal behaviour of trains, [11]. We shall therefore begin with a brief introduction to the basics of the longitudinal rail dynamics model on which the different rail drive models will be constructed.

The basic principal of longitudinal train dynamics is to be found in Newton's Second Law, applied to the longitudinal direction of the train's forward motion:

$$
\Sigma \mathrm{F}=\mathrm{M} \cdot \mathrm{a}
$$

The summatory factor basically comprises two types of forces originating in the drive system " $\mathrm{Ft}$ " and the resistance forces opposed to the train's forward motion, " $\Sigma F_{R}$ ", (fig. 1).

The traction forces are those produced in the wheel-track contact, which will supply the drive systems that will be subsequently constructed. In opposition to the train's motion are the resistance forces opposed to forward motion, " $\Sigma F_{R}$ ", which can be classified under four headings: a) Resistances to the rolling of the wheels on the rails.

b) Passive resistances due to the relative movement between the mechanical elements in contact with one another used to make the train function.

c) Aerodynamic resistances, due to the movement of the train within the air surrounding it.

d) Resistances to the train's forward motion on gradients and curves.

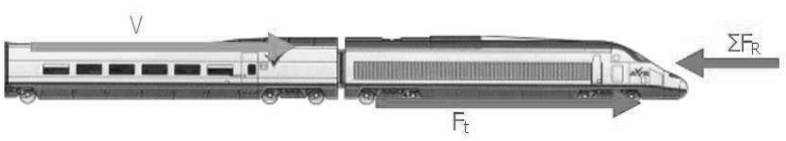

Figure 1. Longitudinal train dynamics.

The phenomena associated with this type of resistance to forward motion are well-known and can be represented together as a whole by using expressions like the one below. This is a unified formula commonly used in modern passenger trains, [1], and [2]:

$$
\Sigma \mathrm{F}_{\mathrm{R}}=\left(266,3+2,8 \cdot \mathrm{V}+0,0517 \cdot \mathrm{V}^{2}\right)+(\mathrm{rg}+500 / \mathrm{R})(\mathrm{L}+\mathrm{Q})
$$

Where " $\mathrm{V}$ " is the speed of the train in $(\mathrm{Km} / \mathrm{h})$, " $\mathrm{rg}$ " is the inclination of the gradient in $(\%)$, " $R$ " is the curve radius in $(\mathrm{m})$, "L" is the weight of the locomotives in (Tm) and "Q" is the towed weight or the weight of the coaches in (Tm). The total resistance force is given by " $\Sigma F_{R}$ " in daN.

Figure 2, shows the longitudinal train dynamics BondGraph model indicating the three phenomena that appear:

- Longitudinal train motion represented by Inertia port I, whose parameter is the total train mass "M".

- The driving forces supplying the energy required to move the train forward. This phenomenon is represented by the Effort Source port "SE", whose ration is the traction force.

- The resistances to forward motion represented by the Resistance port " $\mathrm{R}$ ". This port will have a variable ratio so that expression in eq. 2 will be fulfilled.

The three ports comprising the Bond-Graph are brought together in a type " 1 "junction, since the three phenomena are produced at the same speed, which is the train's forward speed. 


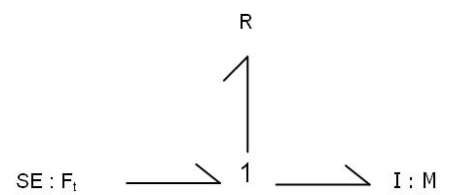

Figure 2. Bond-Graph diagram of longitudinal train dynamics.

\section{RAIL DRIVE SYSTEMS}

Nowadays practically all commercial locomotives are driven by electric motors, [4] and [5]. The electric motors used for rail traction can be direct or alternating current. A direct current electric motor basically consists of two elements; a stator or inductor and a rotor or armature, (see Figure 3.a). The stator's mission is to generate a magnetic field in some windings through which an electric current is made to flow. An electric current is also made to flow in the rotor, and as this is immersed in the magnetic field generated by the stator, the electric current conductor is exposed to mechanical forces that make the rotor spin on its axis. The difference between the various kinds of direct current electric motors lies in the way the stator and rotor circuits are connected, which is known as "excitation type":

a) 'In-series excitation', which consists in connecting the stator and rotor windings in series.

b) 'In-parallel excitation', which consists in connecting the stator and rotor windings in parallel so that they are subjected to the same electrical voltage.

c) And 'independent excitation', where the stator and rotor windings are not connected to each other and are fed by two independent voltage sources.

We shall now go on to study the performance models of the direct current motors with excitation types a) and c), which are those generally used in rail traction.

\section{A. Direct current motors with independent excitation}

Figure 3.a shows the circuit diagram commonly used to depict a direct current motor with independent excitation. Figure 3.b shows the equivalent Bond Graph diagram, [6], [7] and [11]. In addition to the conversion of electrical into mechanical energy, it includes the behaviour of the magnetic fields to take account of the losses produced in them. This does not mean any large increase in model complexity, but to the contrary lets a more precise energy efficiency study be conducted.

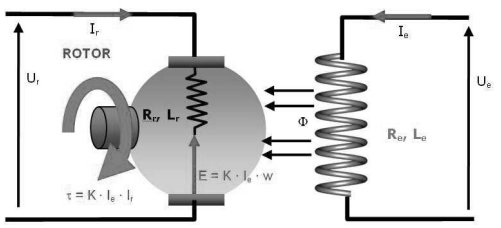

a). Electromechanical diagram.

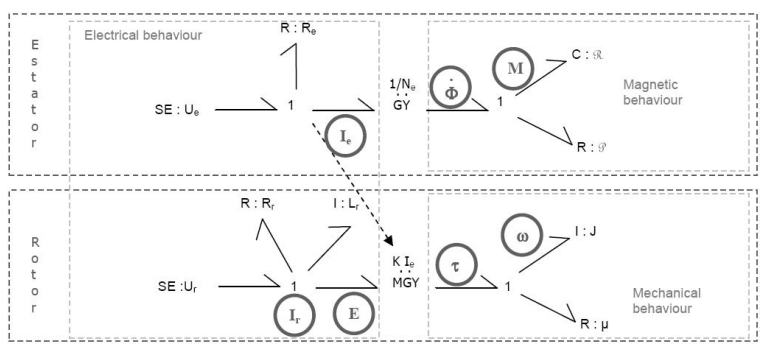

b). Bond-Graph Diagram.

Figure 3. DC motor with independent excitation.

Described below are the general equations and the Bond Graph model shown in Figure 3.b.

We shall first assume that the electric motor takes the electrical energy from the line or catenary. This electrical energy supply is represented using the Effort Forces, "SE", of ratios "Ue" for the stator and "Ur" for the rotor. The electrical current voltage in the circuit of stator "Ue" is used to overcome the ohmic resistors "Re" and to generate a magnetic field, " $\Phi$ " in the winding. The voltage supply is furnished by the Effort Port, "SE" with parameter "Ue", and the ohmic resistors are represented by the Resistance port "R" with parameter "Re". Winding behaviour is usually done using an Inertia port. But in this case, in order to be able to consider the magnetic losses produced in the air-gap and the space between the stator and the rotor, the electrical energy reaching the winding is firstly converted into magnetic energy. This energy transformation is represented in the Bond Graph by the port, "GY" with a ratio of " $1 / \mathrm{N}_{\mathrm{b}}$ ".

The equations governing the transformation of electrical energy into magnetic energy in the stator winding are:

$$
\begin{aligned}
& \mathrm{N}_{\mathrm{b}}(\mathrm{d} \Phi / \mathrm{dt})=\mathrm{U}_{\mathrm{b}} \\
& \mathrm{M}=\mathrm{N}_{\mathrm{b}} \cdot \mathrm{I}_{\mathrm{e}}
\end{aligned}
$$

Where " $\Phi "$ is the magnetic flux generated in the stator winding, "Ub" is the voltage to which it is subjected and " $\mathrm{Nb}$ " is its number of turns. " $\mathrm{M}$ " is the induced magnetomotive force and "Ie" is the electric current strength in the winding.

In the electrical field, the stator winding is represented in the Bond Graph by a Compliance port " $C$ ", in ratio to the reluctance of the magnetic field " $R$ ", in such a way that the relation ship between the flux of the magnetic field and the magnetomotive force " $\mathrm{M}$ " is given by the expression:

$$
M=\int R\left(\frac{d \Phi}{d t}\right) d t
$$

Where, "R" is the Reluctance of the space or material through which the magnetic field crosses. This reluctance can be calculated using the following expression:

$$
\mathrm{R}=1 /(\mathrm{A} \cdot \mu)
$$


In previous equation (6), " $\mathrm{A}$ " is the area crossed by the lines of magnetic flux, "l" is the length of the lines of magnetic flux and " $\mu$ " is the magnetic permeability of the material crossed by the magnetic field.

For small values of flux " $\Phi$ ", the magnetic permeability may be deemed to take on constant values. However, as the magnetic flux grows, the magnetic permeability diminishes due to the saturation produced in the material crossed by the magnetic field. As a result, the magnetic reluctance increases and the relationship between the flux " $\Phi$ " and the magnetomotive force " $\mathrm{M}$ ", ceases to be linear.

Coming back to the Bond Graph, in the magnetic zone, the Resistance port " $R$ " with a ratio of "P" represents the magnetic field losses produced in the air-gap of the stator and in the space between the stator and rotor.

Let us now analyse the electric circuit of the rotor or armature in Figure 3.a. The feed voltage in the "Ur" rotor circuit is supplied by an Effort Source port "SE". In this case, the electrical energy is used to overcome the ohmic resistors represented by the Resistance port "R : Rr", in setting up the magnetic field of the winding represented by the Inertia port "I" with inductance parameter "Lr", and in overcoming the counter electromotive force " $E$ " induced by the stator's magnetic field that causes the rotor to spin. All these elements described are subjected to the same current intensity of the rotor circuit "Ir", for which reason they are connected in a " 1 "Junction.

Due to the rotor's current movement "Ir" at the core of the magnetic field generated by the stator " $\Phi "$, mechanical forces appear that make the rotor spin. The equations governing the transformation of electrical into mechanical energy at the core of the rotor, [6] and [11], are:

$$
\begin{aligned}
& \tau=\mathrm{K} \cdot \mathrm{I}_{\mathrm{e}} \cdot \mathrm{I}_{\mathrm{r}} \\
& \mathrm{E}=\mathrm{K} \cdot \mathrm{I}_{\mathrm{e}} \cdot \mathrm{W}
\end{aligned}
$$

Where " $K$ " is a constant, " $\tau$ " is the motor torque generated in the rotor and " $\mathrm{w}$ " is its angular velocity.

These electrical into mechanical energy transformation equations are represented in the Bond Graph by the "MGY" port with variable ratio " $\mathrm{K}$ Ie". The connection between the Bond Graph of the stator and rotor is produced through the current intensity "Ie". This connection is represented by a conventional broken line.

In the magnetic field, the energy is inverted on overcoming the rotation inertia of the rotor, represented by the Inertia port "I", whose parameter is the moment of inertia of the rotor " $J$ ". In addition, the friction losses are represented in the rotor shaft supports by the Resistance port " $\mathrm{R}$ " whose parameter is the viscous or Coulomb coefficient " $\mu$ ".

Figure 4 shows the connection between the electric motor Bond Graph in Figure 4.b, and the Bond Graph modelling the longitudinal behaviour of the train depicted in Figure 2. The motor picks up the electrical energy supplied by the catenary to transform it into mechanical rotation energy. This rotation energy is associated with Junction " 1 " marked by a letter " $A$ " in Figure 4. The motor is connected to the locomotive's drive wheels which transform the mechanical rotation energy into linear mechanical energy, in accordance with the following expression:

$$
\begin{gathered}
\mathrm{F}_{\mathrm{t}} \cdot \mathrm{V}=\tau_{\mathrm{u}} \cdot \mathrm{W} \\
\mathrm{F}_{\mathrm{t}}=\tau_{\mathrm{u}} / \mathrm{r} \\
\mathrm{V}=\mathrm{w} / \mathrm{r}
\end{gathered}
$$

Where "Ft" represents the total traction force supplied by the wheel in contact with the rails and "V" is the train's longitudinal velocity.

This energy transformation is represented in the Bond Graph by the Transformer "TF:1/r" port, which takes the useful " 1 " junction electric motor output torque " $\tau_{u}$ ", marked by an " $A$ " in Figure 4, and transforms it into the traction force "Ft". In this case, the energy transformation is produced without losses, since the losses produced in the motor rotor are already taken into account in the Bond Graph in Figure 3.b, and the energy losses produced in the wheelrail contact have already been taken into account in the Bond Graph in Figure 2, included in Eq.8 which models the Resistance port "R".

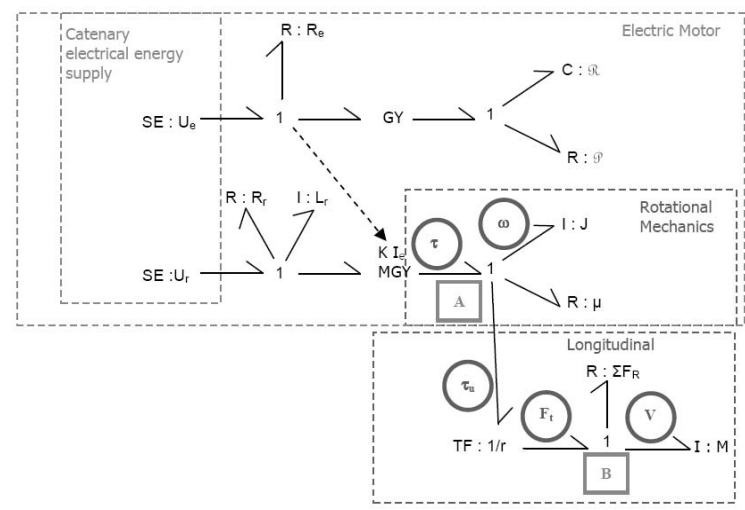

Figure 4. DC rail traction system with indep. excitation by Bond Graph.

The connection with the Bond Graph in Figure 2, is carried out by taking the Transformer "TF:1/r" output path up to the junction "1", marked by a "B" in Figure 4. Finally, the "SE: Ft" Effort Source, which originally supplied the driving force "Ft", is eliminated for obvious reasons.

\section{B. Direct current motors with in-series excitation}

These motors are very similar to direct current motors with independent excitation. The main difference is that the stator and rotor circuits are connected in series. Therefore, the current flowing through both circuits is the same and is also that which induces the magnetic flux that excites the rotor. As to all else, everything mentioned for the motor with independent excitation is applicable to the motor with inseries excitation.

Figure 5.a, shows the electromechanical diagram for a direct current electric motor with in-series excitation, and Figure 5.b. shows the corresponding Bond Graph diagram. 


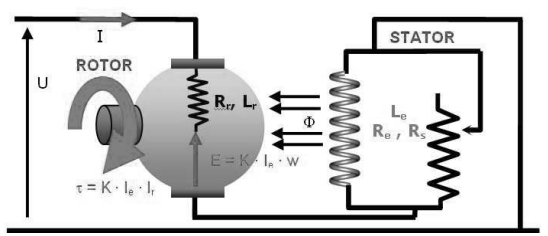

a). Electromechanical diagram.

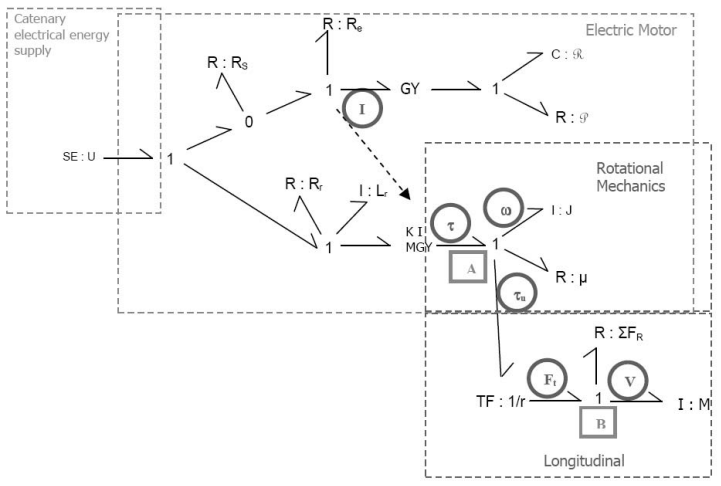

b). Bond-Graph Diagram.

Figure 5. DC motor with in-series excitation rail drive system.

\section{Three-phase alternating current motors}

The third type of motor used for rail traction is the asynchronous three-phase alternating current motor. This type of motor is becoming more and more used as it has the advantage of not having a collector, and, therefore, maintenance is greatly reduced.

Figure 6 shows the equivalent electrical circuit for each of the three-phase motor phases. The Resistor "Re" and the winding "Le" represent the behaviour of the stator circuit. The Resistor "R' $r$ " and the winding "L' $r$ ", reduced to the stator circuit, represent the rotor circuit behaviour. The Resistor "Rp" and the winding "Lp" represent the losses of hysteresis produced in the air-gap and the magnetic flux losses produced in the stator and rotor. Finally, the resistor " $\mathrm{R}$ ' $\mathrm{C}$ " is the equivalent load resistance that models the effect of the mechanical energy produced by each motor phase. The electric power dissipated in the resistor " $\mathrm{R}$ ' $\mathrm{C}$ " is equivalent to the power generated by the electric motor in each of its phases.

Figure 7 shows the Bond-Graph model for the complete asynchronous three-phase alternating current motor. Each of the central horizontal branches in the Bond-Graph model represent each of the motor's phases, taking the equivalent electric circuit shown in Figure 6. The three phases are subjected to an alternating "U" current, $120^{\circ}$ out of phase, using the Metatransformer ports shown to the left. The mechanical power generated by each phase is modelled by the "MGY" ports shown to the left. This rotational mechanical power is added to the " 1 " junction shown to the extreme right of the Bond Graph so it can be applied to the motor shaft modelled by the Inertia port "I" with "J" parameter. The friction losses are also taken into account, and these are represented in the Resistance port " $R$ " with " $\mu$ " parameter.

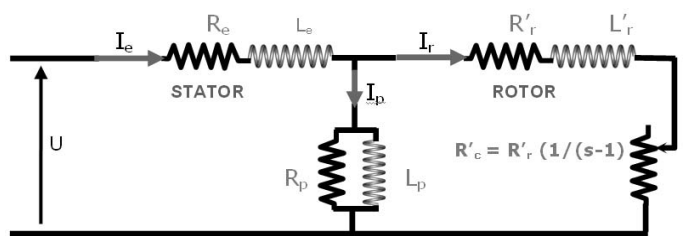

a). Electromechanical diagram.

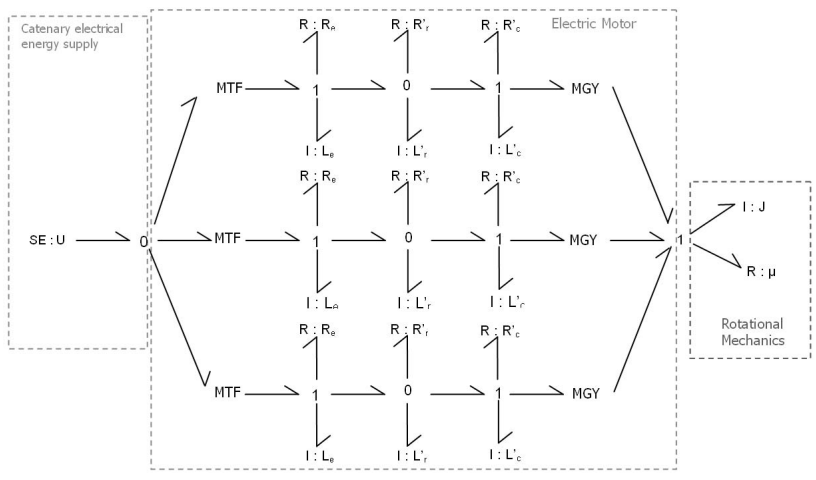

b). Bond-Graph Diagram.

Figure 6. Three-phase AC rail traction system. Bond Graph model.

\section{REGUlATING THE MOTORS.}

Firstly, in order to understand in which direction to regulate the motors, we shall study the characteristic motor and train operation curves shown in Figure 8. The former show the relation between the torque and speed supplied by the motor, and the latter represent the torque requirements of the train depending on its running speed. The electric motor curve " $\tau$-w" shown, corresponds to a motor with constant resistance in the stator and the rotor. The characteristic rail traction curve is a perfect hyperbola for high running speeds, but for low speeds it becomes horizontal since the torque cannot exceed the maximum torque due to the constraints of adherence between the wheels and the rails.

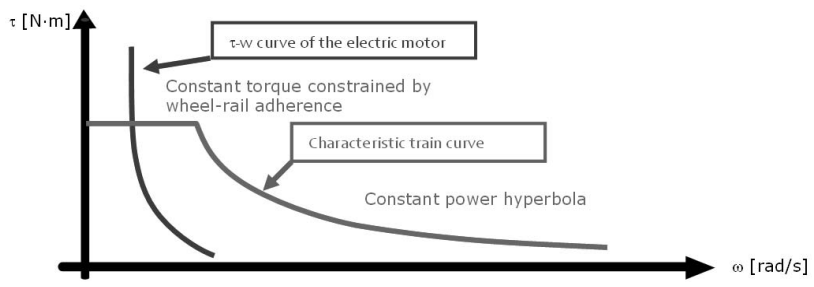

Figure 7. Electric motor " $\tau$-w" and characteristic rail traction curves.

If we study Figure 8 the lack of adaptation between the two curves can be appreciated. This makes an additional regulation of the electric motor necessary to enable the " $\tau$ w" curve to be adapted with the greatest possible similitude to the characteristic traction curve of the train.

In direct current motors with independent excitation in order to obtain an approximately constant motor torque in the start-up, the value of the intensity flowing in the rotor needs to be reduced. This is achieved by inserting resistors in 
series into the rotor. When the start-up period has been exceeded, reaching the constant power hyperbola zone, (see Figure 8), in order to regulate the direct current electric motor the method used is called shunting. This consists in mounting a variable resistor in series with the motor stator (See Figure 3.a). This succeeds in reducing the intensity of the current flowing in the stator "Ie", reducing the magnetic flux " $\Phi$ ", the electromotive force induced in the rotor " $E$ " and the motor torque " $\tau$ " found on the shaft. As a result of this, the " $\tau$-w" curves of the motor, (blue in Figure 8), will move towards the right.

In the case of direct current motors with in-series excitation, the start-up torque is regulated in the same way as with motors with independent excitation by placing a greater resistance in series to the rotor circuit. Having reached the constant power hyperbola zone, the procedure also consists in reducing the stator current by shunting (see Figure 5.a). But as the rotor and stator circuits are working in series in this case, the shunt resistors are mounted in parallel to the stator circuit. By so doing, the stator current is changed without it affecting the rotor current.

Regarding the asynchronous alternating current motors, Figure 9 shows different motor torque curves compared to rotation speed for the three-phase motor, fitted to the characteristic train traction curve. Control of these motors for fitting the curve to the train's requirements is accomplished by varying the feed voltage and the current frequency by using electronic equipment known as choppers.

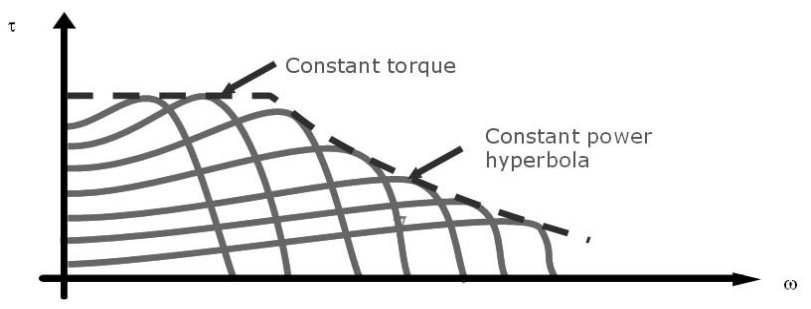

Figure 8. Different " $\tau$-w” curves fitted to the characteristic train curve.

From a train-braking point of view, apart from mechanical disc or shoe systems, there are two braking systems that we could call electrical: rheostatic braking and regenerative braking.

In both cases, it is a question of using the electric motors as generators to transform mechanical energy into electric current. The main difference between the two systems is that the rheostatic brake sends the current to some resistors that dissipate the electric current in the form of heat, while regenerative braking sends the electric current to the catenary for it to be reused to drive other trains.

\section{RESULTS}

In order to study the energy efficiency of the three rail drive systems considered, a typical train and a typical route were taken whose specifications are shown in Table I. Only regenerative braking was considered in the simulations as it is obviously the most energy-efficient in every case.
A typical route was simulated with a total length of 68 $\mathrm{Km}$, with a top speed of up to $300 \mathrm{Km} / \mathrm{h}$ over certain sections, and with different gradients and curve radiuses.

Table I. Train specifications used in the simulations.

\begin{tabular}{|l|}
\hline General train specifications: \\
\hline Train type: High speed. \\
Maximum speed: $300,0 \mathrm{Km} / \mathrm{h}$ \\
Track width: $1.437 \mathrm{~mm}(+5,0 \mathrm{~mm}:-3,0 \mathrm{~mm})$ \\
Maximum number of passengers: 337,0 \\
Maximum static mass per axle under normal load: $17,2 \mathrm{Tm}$. \\
Maximum dynamic load per wheel: $175,0 \mathrm{kN}$. \\
Maximum motor shaft power for conplete train: $8.800 \mathrm{kTV}$ \\
Train composition: 2 locomotives at each end, pulling 8 coaches on 9 bogies. \\
Compressed air disc brake. \\
Electric regenerative braking. \\
\hline Locomotive specifications: \\
\hline Total length: $22,150 \mathrm{~m}$. \\
Total width: $2,814 \mathrm{~m}$. \\
Maximum height from rail: $4,1 \mathrm{~m}$. \\
Unit mass: 67,8 Tm. \\
Distance between bogie axles: $3,0 \mathrm{~m}$. \\
Distance between bogies: $14,0 \mathrm{~m}$. \\
Number of drive shafts: 4 \\
Nominal diameter of wheels: $0,920 \mathrm{~m}$. \\
Maximum driving force per axle: $67,5 \mathrm{kN}$. \\
\hline Motor specifications: \\
\hline Type of feed: $25 \mathrm{k}$ \& $50 \mathrm{~Hz}$ alternating curr ent or $3 \mathrm{kV}$ Direct Current. \\
Nominal power: $2.200 \mathrm{~kW}$ \\
Type of motor: asynchronous three-phase alternating current motors or direct current motors. \\
Dynamic brake: regenerative type, $3 / 4$ of maximum braking power. \\
\hline
\end{tabular}

Figure 9 contains a summary of the simulation results showing the curves for the total traction forces " $F$ " versus speed of the train "V", and electrical energy consumed on the train's route. The slight dip at the end of the curves can be seen resulting from the regenerative braking which transforms part of the train's mechanical energy into electrical energy and returns it to the catenary.
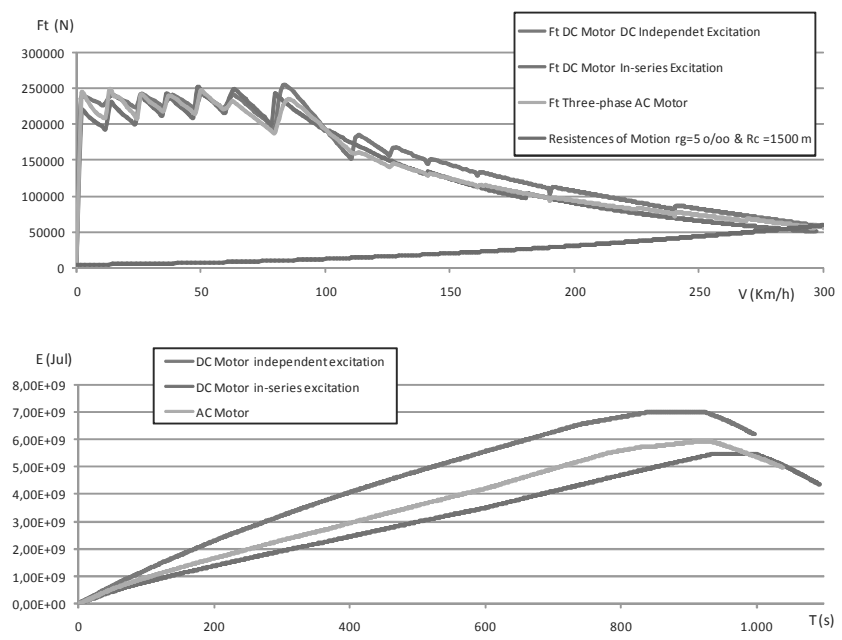

Figure 9. Simulation result summary curves on the route for the different types of motor.

In curves "Ft-V" small jumps can be observed due to regulation of the operation of each engine in terms of its speed " $\omega$ " by intervals. Specifically, for both types of DC motors, this regulation has been made by varying the Shunt resistors for speed intervals. For AC motor, the regulation was made by varying the Shunt resistors and frequency of current, at equal intervals of speed in the case of DC motors. 
Also, for each type of motor, the relation between the useful mechanical energy obtained from the train and the total electrical energy consumed was calculated. The energy performance for each type of motor was also obtained, as shown in Table II.

Table II. Performance of the three drive systems for the route studied.

\begin{tabular}{|l|c|}
\hline \multicolumn{1}{|c|}{ Drive system } & Performance \\
\hline Electric power motor with independent excitation & $81.8 \%$ \\
\hline Electric power motor with in-series excitation & $88.5 \%$ \\
\hline Asynchronous alternating current motor & $92.3 \%$ \\
\hline
\end{tabular}

\section{CONCLUSIONS}

As the first important conclusion, the models for three rail traction motors were constructed: direct current motors with independent and in-series excitation, and an asynchronous alternating current motor.

In order to perform the simulations in realistic conditions it was necessary to model the systems regulating the motor, train speed and the regenerative braking system.

The Bond-Graph has once again demonstrated its great potential for constructing compact models where different fields of physics and technology come together. In the specific case of this work, electricity, magnetism and mechanics.

The behavior of different traction systems was simulated with the same systems regulating the motor and on the same route type. An important difference of system regulating the AC motors respect for DC motors, is the possibility of varying the frequency of the current. Obviously, this is not able in the DC motors.

Moreover, algorithms must be developed to regulate the engines in order to eliminate small jumps detected in the curves "FT-V". In this work, the regulation was made by varying the shunt resistors for certain speed ranges. Obviously, in further research, it will be possible to obtain a continuous variation of shunt resistor and frequency as a function of engine speed.

The performance of each system was calculated as the quotient of the useful mechanical energy obtained in the displacement of the train and the total electrical energy consumed. The best performance in relative terms from the simulation of the three types of motor was shown to be that of the asynchronous three-phase motor. The direct current motor with independent excitation had performance worst compared to the other two types of motors.

On the other hand, DC motor with independent excitation has some special advantages over the other too. The most favourable force-velocity curve and allows faster acceleration.

These performances must be understood as being for a train of the characteristics considered and for the typical route adopted. In reality, trains will be able to offer even better performances depending on the route and how the motor regulation is optimized and the speed regulated on the journey. For this reason, the performances obtained should be understood in terms relative to the conditions applied in the simulations.

It is necessary to point that this is a first step study of the energy consumption, performance of railway traction systems and its environmental impact. No empirical data by energy consumption has been able to use. But theoretical models helped to understand motors behavior and regulation. Subsequent studies involving empirical data from validation tests will clarify and confirm strongs and weaks between the different electric motors.

\section{A. Future investigation lines.}

As result of before conclusions new investigation lines are open:

- More precise models focusing in energy losses must be developed.

- Standard validation test must be defined and performed or empirical validation data must be used.

- More accuracy regulation motors systems must be studied and developed, in order to improve its performance.

- Automation motors systems must be developed in order to optimize the energy consumption and decrease its environmental impact.

\section{REFERENCES}

[1] Álvarez, D.; Luque, P. (2002). "Ferrocarriles". Servicio de Publicaciones de la Universidad de Oviedo, Oviedo (España).

[2] Aparicio, $\mathrm{F}$ et all. (2008). "Ingeniería del Transporte". CIE Inversiones Editoriales DOSSAT 2000. ISBN: 978-84-96437-82-1.

[3] Esperilla, J.J., Romero, G., Félez, J., Carretero, A. (2007). "Bond Graph simulation of a hybrid vehicle". Actas del International Congress of Bond Graph Modeling, ICBGM'07.

[4] Hata, H. (1998). "Railway Technology Today 4. What Drives Electric Multiple Units?”. Japan Railway \& Transport Review 17.

[5] Iwnicki, S. (2006). "Handbook of Railway Dynamics". Ed. Taylor \& Francis Group. London.

[6] Karnopp, D. (2005). "Understanding Induction Motor State Equations Using Bond Graphs". Actas del International Congress of Bond Graph Modeling, ICBGM'05.

[7] Karnopp, D.; Margolis, D.; Rosenberg, R. (2000). "System Dynamics: Modeling and Simulation of Mechatronic systems". Ed. John Wiley \& Sons, LTD $\left(2^{\mathrm{a}}\right)$. Chapter 11. ISBN: 978-0-471-333012.

[8] Kato, I.; Terumichi, Y.; Adachi, M.; Sogabe, K. (2005). "Dynamics of Track/Wheel Systems on High-Speed Vehicles". Journal of Mechanical Science and Technology, Vol 19, No 1, <Special Edition> pp 328-335.

[9] Pfeiffer, F.; Wriggers, P. "Lecture Notes in Applied and Computational Mechanics". Ed. Springer. Vol. 40. 2008.

[10] Umesh, B.; Umanand, L. (2008). "Bond graph model of doubly fed three phase induction motor using the Axis Rotator element for frame transformation". Simulation Modeling Practice and Theory 16, Pag. 1704-1712.

[11] Vera, C. (2004). "Curso de Ferrocarriles". Escuela Técnica Superior de Ingenieros Industriales de Madrid. Universidad Politécnica de Madrid. 